\title{
Endoscopic Endonasal Transsphenoidal Pituitary Tumors Approach: Nuances of Neurosurgical Technique
}

\section{Abordagem endoscópica endonasal transesfenoidal para tumores hipofisários: detalhes da técnica neurocirúrgica}

\author{
Flávio Ramalho Romero ${ }^{1}$ Jose Vicente Tagliarini ${ }^{2}$ Vânia dos Santos Nunes ${ }^{3}$ Marco Antônio Zanini ${ }^{4}$ \\ ${ }^{1}$ Hospital das Clínicas, Universidade Estadual Paulista (UNESP), \\ Botucatu, Brazil \\ 2 Department of Otolaryngology, UNESP, Botucatu, Brazil

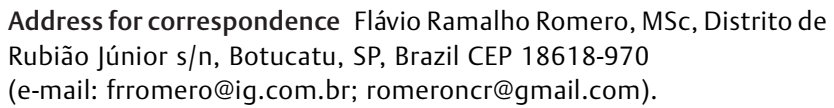

${ }^{3}$ Department of Endocrinology, UNESP, Botucatu, Brazil

${ }^{4}$ Department of Neurosurgery, UNESP, Botucatu, Brazil

Arq Bras Neurocir 2015;34:139-143.
Abstract
Keywords
- pituitary tumors
- transsphenoidal approach
- skull base tumors
Resumo
Palavras chave
- tumores hipofisários
- acesso transesfenoidal
- tumores de base de crânio

Pituitary tumors are responsible for 7 to $17 \%$ of all intracranial lesions. Over the past decade, advances in endoscopic microsurgical techniques have resulted in an increasingly aggressive endonasal approach to tumors of the midline skull base. We present our series emphasizing technical nuances of endoscopic endonasal transsphenoidal approach to treat pituitary adenomas.

Tumores hipofisários são responsáveis por 7 a 17\% de todas as lesões intracranianas. Durante a última década, avanços nas técnicas microcirúrgicas endoscópicas resultaram no aumento de acessos endonasais agressivos para tumores de base de crânio de linha média. Apresentamos nossa série de casos, com ênfase nos detalhes técnicos do acesso endoscópico endonasal transesfenoidal para o tratamento de tumores da hipófise.

\section{Introduction}

Pituitary adenomas represent 7 to $17 \%$ of all intracranial tumors. ${ }^{1}$ Prevalence of asymptomatic incidental pituitary adenomas is approximately $16.7 \%$ when combing the results from autopsy and magnetic resonance imaging (MRI) studies, but few of these tumors become symptomatic (prevalence of $19.3 / 100,000$ population). ${ }^{2}$ It is a benign histologic tumor arising from adenohypophyseal cells in the anterior pituitary. Sometimes may enlarge and invade surrounding structures. ${ }^{3}$ Pituitary adenomas frequently produce hormones that lead to endocrinologic syndromes (hyperprolactinemia, acromegaly, Cushing disease, and, rarely, hyperthyroidism), allowing early diagnosis of small received

September 29, 2014

accepted

March 31, 2015
DOI http://dx.doi.org/

10.1055/s-0035-1554737. ISSN 0103-5355.
Copyright $\odot 2015$ by Thieme Publicações License terms Ltda, Rio de Janeiro, Brazil 
lesions. ${ }^{4}$ Alternatively, pituitary adenomas may be nonfunctioning and present with symptoms caused by local mass effect, including visual loss, hydrocephalus, and hypopituitarism. ${ }^{3,4}$

MRI is currently the diagnostic imaging modality of choice for pituitary adenomas. ${ }^{5}$ All patients with pituitary macroadenomas should undergo history, physical, and laboratory evaluations for hormone hypersecretion and for hypopituitarism, and a visual field examination if the lesion abuts the optic nerves or chiasm. ${ }^{6}$ Once the diagnosis is established, some cases of asymptomatic nonfunctional tumors may be treated conservatively, but surgical resection remains the first line of treatment for macroademas and for functional adenomas, except for prolactinomas, which respond well to dopamine agonists. ${ }^{7}$

Over the past decade, advances in endoscopic microsurgical techniques have resulted in an increasingly aggressive endonasal approach to tumors of the midline skull base. ${ }^{8-15}$ Here, we present our series emphasizing technical nuances of endoscopic endonasal transsphenoidal approach to treat pituitary adenomas.

\section{Patient Selection}

We retrospectively reviewed a prospectively collected database of all patients undergoing fully endoscopic endonasal surgery between 2009 and 2014. From this database, we identified all patients whose final pathology revealed pituitary adenoma. At our institution we perform an endonasal transsphenoidal approach as the initial surgery for almost every pituitary adenoma. A total of 92 patients underwent 96 endoscopic procedures.

\section{Operative Technique}

After general anesthesia, patient is placed in prone position with 3-point fixation and routinely received $2 \mathrm{~g}$ intravenous of cephazolin and $50 \mathrm{mg}$ intravenous of hydrocortisone. Lumbar drain and fluorescein $(0.2 \mathrm{~mL}$ of $10 \%$ in $10 \mathrm{~mL}$ of cerebrospinal fluid [CSF]) are not used as routine, only in tumors larger than $2 \mathrm{~cm}$. Under endoscopic view (0-degree, 17-cm, 4-mm scope), the inferior, middle, and superior turbinates are identified, and the mucosa of the middle turbinates is injected with a solution of lidocaine $1 \%$ and epinephrine $(1: 100,000)$. The middle and superior turbinates are retracted laterally, showing the sphenoid ostia bilaterally, that is located $1.5 \mathrm{~cm}$ superior to the posterior choanae on the anterior sphenoid sinus wall. Sometimes, the ostium is covered by mucosa or a supreme turbinate and must be gently retracted laterally or resected if necessary.

The next step regards to nasoseptal flap. We harvest it if the tumor is larger than $2 \mathrm{~cm}$ or extends more than $1 \mathrm{~cm}$ above the planum sphenoidale, making cuts in the septal mucosa $1 \mathrm{~mm}$ above the palate and 2 to $3 \mathrm{~mm}$ bellow the cribriform plate. Then, the mucosa is elevated off the septum, the rostrum of sphenoid sinus and putted into the choana. The most important issue at this point is to preserve the vascular supply from the sphenopalatine artery that is located between the choanal and sphenoid ostia, just few millimeter above the choana (-Fig. 1).

Mucosa around the sphenoid ostium is enlarged with a mushroom punch and Kerrison rongeur. Then, the posterior third of the nasal septum adjacent to the vomer bone and maxillary crest is resected, providing the use of four separate instruments by two nostrils. The mucosa of the sphenoid sinus rostrum is retracted laterally and inferiorly, and the bone is removed with a drill, including the floor and lateral wall of the sphenoid sinus. It is very important to remove all the anterior wall of the sphenoid sinus to provide a comfortable corridor for the endoscope and instruments during the procedure. The main concern at this point is to avoid fracturing the cribriform plate, a common site of iatrogenic CSF leak. Pneumatization of the sphenoid sinus is highly variable, including three types: sellar (80\%), presellar (17\%), and conchal (3\%) configurations. ${ }^{16}$ It is very important to recognize the type of sphenoid sinus before the surgery. A conchal sphenoid sinus has minimal to absent pneumatization and poses an anatomical challenge for endoscopic transsphenoidal surgery.

All sphenoid septations are removed with a drill, and the mucosa is completely removed to avoid a postoperative mucocele under the nasoseptal flap. The sphenoid sinus is divided by complete and incomplete bony septations that have many orientations (vertical, horizontal and oblique), and often are inserted into the carotid artery. ${ }^{16}$ Therefore, a very carefully dissection for avoiding a catastrophic vascular injury is mandatory. Mucosal or venous bleeding is stopped with Gelfoam, gentle pressure, and saline irrigation.

The posterior wall of the sphenoid sinus is brought into full view. Carotid protuberance, optic protuberance, opticocarotid recesses, clivus, sellar floor, tuberculum sellae, and planum sphenoidale are identified. We often start drilling the center of the sellar floor and enlarged the opening between the middle clinoids with Kerrison rongeur. If the sellar floor is thinned by a large tumor, we use a curette to take off the bone. The inferior limit extends down to roughly $1 \mathrm{~mm}$ above the floor of the sella. Superiorly, the limit depends on the tumor extension. In case of an extended transplanum, transtubercular approach is necessary and care is taken with the intercavernous sinus. If necessary, we coagulate the sinus with a bipolar. Then, the bone opening is extended above the level of the diaphragm, and the planum sphenoidale is removed. In most of cases, a 30-degree scope helps achieve adequate upward visualization (-Fig. 2).

In case of cavernous sinus tumor extension, the bone over the sinus is removed with $1-\mathrm{mm}$ Kerrison rongeur. Venous bleeding is stopped using Gelfoam, gentle pressure, and saline irrigation. The course of carotid arteries is identified with preoperative MRI and intraoperative navigation. MicroDoppler is another very useful instrument to localize the carotid arteries.

Dura opening is performed with a cruciate pattern using knifes and scissors. Then, the anterior tumor capsule is dissected free from the dura. The location of normal pituitary gland and stalk must be obtained with preoperative MRI 

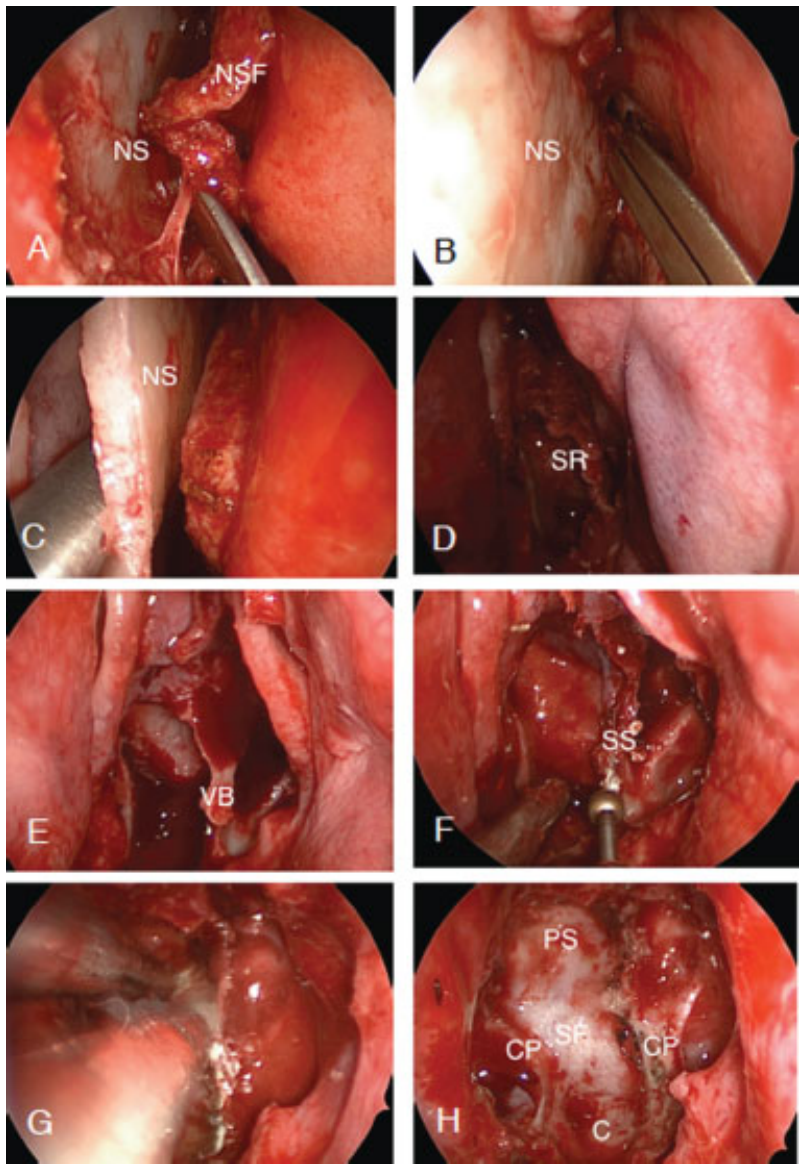

Fig. 1 Nasal dissection. (A) Harvesting the nasoseptal flap. (B) Dissecting the nasoseptal flap from nasal septum. (C) Opening the posterior part of nasal septum. (D) After removing the posterior part of nasal septum and part of rostrum of sphenoidal sinus. (E) Removing the rostrum of sphenoidal sinus, showing the vomer bone. (F) Exposure of cranial base floor, after removing the rostrum of sphenoidal sinus, showing sphenoidal sinus septation. (G) Drilling the sphenoidal sinus septations. $(\mathrm{H})$ Exposure of anterior middle cranial fossa floor, showing clivus, sellar floor, planum sphenoidale, and carotid protuberance. C, clivus; CP, carotid protuberance; NS, nasal septum; NSF, nasoseptal flap; PS, planum sphenoidale; SF, sellar floor; SR, sphenoidal rostrum; SS, sphenoidal septation; VB, vomer bone.

images. Most of the times, the normal gland is draped over the top of the tumor. However, sometimes, it can be pushed laterally or even anteriorly. It is important to plan the safest approach to avoid resecting normal pituitary during the procedure. Also, care must be taken to avoid disconnecting the gland from the stalk.

Internal tumor decompression with suction and ring curettes is helpful in giant macroadenomas. Frozen and permanent specimen is obtained. It is important to start removing the inferior portion of the tumor and then the lateral portion to avoid the suprasellar arachnoid herniation down into the sella. After the inferior and lateral tumor portion is removed, attention is turned to the suprasellar extension. Sometimes, the use of the 30-degree scope and removal of the tuberculum sella and planum sphenoidale facilitate the direct approach to this tumor portion. We prefer to dissect the tumor off the
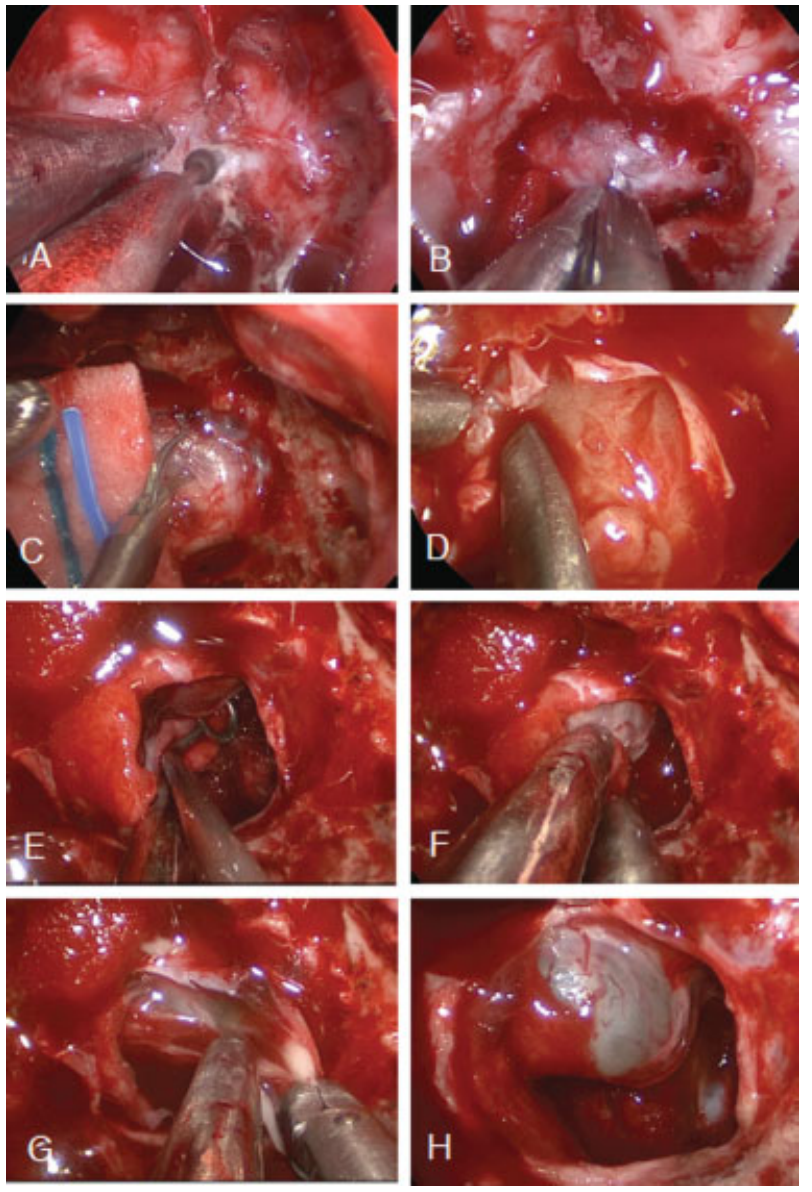

Fig. 2 Tumor resection. (A) Drilling the sellar floor to started the exposure of sellar dura. (B) Initiating the opening of sellar dura. (C) Opening the sellar dura in cruciform pattern. (D) Dissection of tumor capsule from dura. (E) Internal tumor decompression. (F) Lateral tumor capsule dissection from cavernous sinus wall. (G) Tumor capsule dissection from diaphragm sella. (H) Final inspection after tumor resection.

normal gland and arachnoid. Aggressive internal decompression facilitates the access to the superior tumor part. Then, it is possible to dissect over the top of the capsule and push the tumor down off (-Fig. 2).

After the end of resection, a 30- or 45-degree scope is advanced into the cavity to check the absence of any residual tumor. If a residual tumor is visualized, angled instruments can be used to reach residual pieces of tumor.

The next and last step is the closure ( $\mathbf{- F i g . ~} \mathbf{3}$ ). In cases of no CSF leak after the resection, we use Gelfoam held in place
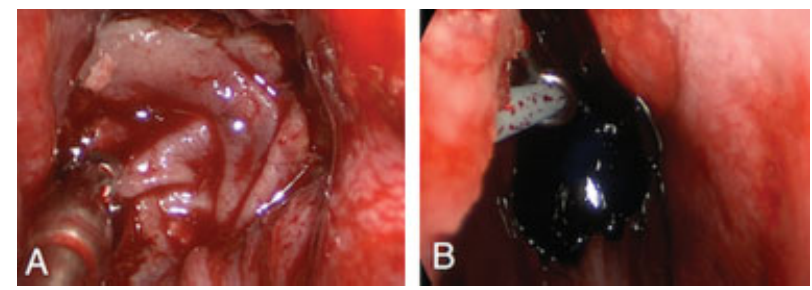

Fig. 3 Closure. (A) Nasoseptal flap is placed to cover the cranial base defect. (B) Fibrin glue is putted over the nasoseptal flap. 
with vomer or nasal cartilage graft (removed during the nasal opening) and fibrin glue. In cases of small CSF leaks, the cavity is filled with fat, a cartilage or vomer graft, and fibrin glue. In cases of large CSF leaks, the defect is first filled with fat, fascia lata, cartilage or vomer graft, covered by a nasoseptal flap and finally fibrin glue and a Foley catheter number 8, maintained for 24 to 48 hours. Large intraoperative CSF leak also undergo lumbar drainage for 24 to 48 hours postoperatively and low doses of heparin to prevent deep venous thrombosis.

\section{Discussion}

In 1914, Cushing described the first report of transsphenoidal approach to the sella turcica, ${ }^{17}$ but only with the introduction of operative microscopy and radiofluoroscopy, the transsphenoidal approach became popular. Modifications to minimize mucosal trauma and patient discomfort were originally described by Hirsch (apud Cohen-Gadol) ${ }^{18}$ and popularized by Griffith and Veerapen ${ }^{19}$ as the direct endonasal approach. Endoscope was first used in 1963 by Guiot et al to explore the contents of the sella turcica, ${ }^{20}$ but only in 1996, Jho and Carrau described the first purely endoscopic endonasal transsphenoidal approach to this region. ${ }^{21}$ Based on data, endoscopic endonasal transsphenoidal surgery has gained increasing acceptance by otolaryngologists and neurosurgeons. In many centers throughout the world, this technique is now routinely used for the same indications as the conventional microsurgical technique.

The endoscope provides a bright and spacious surgical field, and the surgeon can easily confirm structural details by increasing magnification. Proponents of this method contend that despite the loss of stereoscopic vision, the field of view is better than that achieved with a microscope because the light source and lens are closer to the lesion. ${ }^{22-24}$ With recent advancements in optical instruments, surgical indications have expanded beyond sellar lesions to lesions in the anterior skull base, cavernous sinus, or clivus. However, this extended approach presents difficulties during the operation, and it can be unclear, which surgical indications warrant this approach; therefore, surgeons need to become skilled in this approach and be aware of improvements in equipment, as well as of the various diseases that can be successfully treated with this approach. ${ }^{23,24}$

The first principle in both understanding and successfully achieving good results with the endoscopic endonasal approach is a close collaboration between the otolaryngologist with experience in endoscopic sinus surgery/skull base surgery and the neurosurgeon with experience in performing transsphenoidal pituitary and skull base surgery. The approaches derive from the union of these two perspectives. ${ }^{14}$

Several authors have discussed the potential outcomes of the endoscopic technique. DeKlotz et $\mathrm{al}^{25}$ used a meta-analysis to reveal the superior rate of gross total resection (GTR) (79 vs. $65 \%, p<0.0001$ ) as well as the lower rates of CSF leak ( 5 vs. $7 \%$, $p<0.01$ ), septal perforation (0 vs. 5\%), and postoperative

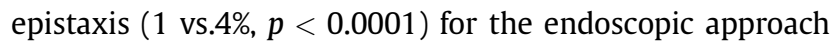
compared with the sublabial approach. Rotenberg et $\mathrm{al}^{26}$ concluded that the two approaches had similar outcomes (GTR, hormonal abnormality resolution), but endoscopic approach was associated with lower complication rates as well as a shorter hospital stay and length of operation. Goudakos et $\mathrm{al}^{27}$ demonstrated that the rates of GTR/CSF leakage were similar between the two techniques. However, the study also revealed a lower incidence of postoperative diabetes insipidus (DI) and a shorter hospital stay in the studied endoscopic groups. Other systematic reviews also support the safety and short-term efficacy of endoscopic pituitary surgery. ${ }^{28}$ Interestingly, Ammirati et $\mathrm{al}^{29}$ recently reported a meta-analysis, concluding that endoscopic removal of pituitary adenoma, in the short term, does not seem to confer any advantages over the microscopic technique and that the incidence of vascular complications was higher with endoscopic than with microscopic removal of pituitary adenomas. In our practice, endoscopic endonasal transsphenoidal approach was very effective at treating pituitary tumors.

\section{Conclusion}

With the incremental acquisition of new technology and skills and experience, endoscopic endonasal approaches have an acceptable safety profile in patients presenting with pituitary tumors.

\section{References}

1 Kovacs K, Horvath E. Pathology of pituitary tumors. Endocrinol Metab Clin North Am 1987;16(3):529-551

2 Ezzat S, Asa SL, Couldwell WT, et al. The prevalence of pituitary adenomas: a systematic review. Cancer 2004;101(3):613-619

3 Scheithauer BW, Kovacs KT, Laws ER Jr, Randall RV. Pathology of invasive pituitary tumors with special reference to functional classification. J Neurosurg 1986;65(6):733-744

4 Hofstetter C, Anand VK, Schwartz TH. Endoscopic transsphenoidal pituitary surgery. Oper Tech Otolaryngol 2011;22:206-214

5 Kulkarni MV, Lee KF, McArdle CB, Yeakley JW, Haar FL. 1.5-T MR imaging of pituitary microadenomas: technical considerations and CT correlation. AJNR Am J Neuroradiol 1988;9(1):5-11

6 Freda PU, Beckers AM, Katznelson L, et al; Endocrine Society. Pituitary incidentaloma: an endocrine society clinical practice guideline. J Clin Endocrinol Metab 2011;96(4):894-904

7 Casanueva FF, Molitch ME, Schlechte JA, et al. Guidelines of the Pituitary Society for the diagnosis and management of prolactinomas. Clin Endocrinol (Oxf) 2006;65(2):265-273

8 Cappabianca P, Cavallo LM, Esposito F, De Divitiis O, Messina A, De Divitiis E. Extended endoscopic endonasal approach to the midline skull base: the evolving role of transsphenoidal surgery. Adv Tech Stand Neurosurg 2008;33:151-199

9 Cappabianca P, Cavallo LM, Colao A, de Divitiis E. Surgical complications associated with the endoscopic endonasal transsphenoidal approach for pituitary adenomas. J Neurosurg 2002;97(2):293-298

10 de Divitiis E, Cappabianca P, Cavallo LM. Endoscopic transsphenoidal approach: adaptability of the procedure to different sellar lesions. Neurosurgery 2002;51(3):699-705, discussion 705-707

11 Kassam AB, Prevedello DM, Carrau RL, et al. Endoscopic endonasal skull base surgery: analysis of complications in the authors' initial 800 patients. J Neurosurg 2011;114(6):1544-1568

12 Gardner PA, Kassam AB, Snyderman CH, et al. Outcomes following endoscopic, expanded endonasal resection of suprasellar craniopharyngiomas: a case series. J Neurosurg 2008;109(1):6-16 
13 Jho HD. Endoscopic transsphenoidal surgery. J Neurooncol 2001; 54(2):187-195

14 Schwartz TH, Fraser JF, Brown S, Tabaee A, Kacker A, Anand VK. Endoscopic cranial base surgery: classification of operative approaches. Neurosurgery 2008;62(5):991-1002, discussion 10021005

15 Snyderman CH, Pant H, Carrau RL, Prevedello D, Gardner P, Kassam $\mathrm{AB}$. What are the limits of endoscopic sinus surgery?: the expanded endonasal approach to the skull base Keio J Med 2009;58(3):152-160

16 Singh A, Wessell AP, Anand VK, Schwartz TH. Surgical anatomy and physiology for the skull base surgeon. Oper Tech Otolaryngol 2011;22:184-193

17 Cushing H. The Weir Mitchell Lecture. Surgical experience with pituitary disorders. JAMA 1914;63:1515-1525

18 Cohen-Gadol AA, Liu JK, Laws ER Jr. Cushing's first case of transsphenoidal surgery: the launch of the pituitary surgery era. J Neurosurg 2005;103(3):570-574

19 Griffith HB, Veerapen R. A direct transnasal approach to the sphenoid sinus. Technical note. J Neurosurg 1987;66(1): 140-142

20 Guiot G, Rougerie J, Fourestier M, Fournier A, Comoy C, Vulmiere J. Une nouvelle technique endoscopique: explorations endoscopiques intracraniennes. Presse Med 1963;72:1225-1231

21 Jho HD, Carrau RL. Endoscopy assisted transsphenoidal surgery for pituitary adenoma. Technical note. Acta Neurochir (Wien) 1996;138(12):1416-1425
22 Yano S, Hide T, Shinojima N, Hasegawa Y, Kawano T, Kuratsu J. Endoscopic endonasal skull base approach for parasellar lesions: Initial experiences, results, efficacy, and complications. Surg Neurol Int 2014;5:51-53

23 Laufer I, Anand VK, Schwartz TH. Endoscopic, endonasal extended transsphenoidal, transplanum transtuberculum approach for resection of suprasellar lesions. J Neurosurg 2007; 106(3):400-406

24 Cavallo LM, Prevedello DM, Solari D, et al. Extended endoscopic endonasal transsphenoidal approach for residual or recurrent craniopharyngiomas. J Neurosurg 2009;111(3):578-589

25 DeKlotz TR, Chia SH, Lu W, Makambi KH, Aulisi E, Deeb Z. Metaanalysis of endoscopic versus sublabial pituitary surgery. Laryngoscope 2012;122(3):511-518

26 Rotenberg B, Tam S, Ryu WH, Duggal N. Microscopic versus endoscopic pituitary surgery: a systematic review. Laryngoscope 2010;120(7):1292-1297

27 Goudakos JK, Markou KD, Georgalas C. Endoscopic versus microscopic trans-sphenoidal pituitary surgery: a systematic review and meta-analysis. Clin Otolaryngol 2011;36(3): 212-220

28 Gao Y, Zhong C, Wang Y, et al. Endoscopic versus microscopic transsphenoidal pituitary adenoma surgery: a meta-analysis. World J Surg Oncol 2014;12:94-99

29 Ammirati M, Wei L, Ciric I. Short-term outcome of endoscopic versus microscopic pituitary adenoma surgery: a systematic review and meta-analysis. J Neurol Neurosurg Psychiatry 2013; 84(8):843-849 